\title{
As caricaturas de Maomé e a liberdade de expressão*
}

Manuel Atienza ${ }^{1}$ Roberto Freitas Filho ${ }^{2}$

Publicado originalmente em Podemos hacer más: otra forma de pensar el Derecho. Madrid: Editorial Passos Perdidos, 2013, Capítulo segundo. Tradução Roberto Freitas Filho, tradução e publicação autorizadas pelo autor. Recebido em: 29/05/2015. Aprovado em: 31/05/2015.

1 Catedrático de Filosofia do Direito na Universidade de Alicante - Espanha .

2 Tradutor da Obra é Doutor em Direito pela USP e foi professor visitante das Universidades de Gradada e Salamanca, ambas na Espanha. Tradução e publicação autorizadas pelo autor.

\section{Resumo}

O texto trata de questões relativas à liberdade de expressão no contexto europeu, em que se manifestam cotidianamente problemas de limites à manifestação de pensamento e expressões artísticas em face de crenças sagradas e dogmas religiosos. A experiência do Tribunal Europeu de Direitos Humanos - TEDH - é tomada como objeto de reflexão, sob o conceito crítico de coerência das decisões, aproximação utilizada pelo autor para produzir uma proposta de sugestão de tratamento do problema pelos tribunais. A solução proposta é condicional e baseada em uma tipologia ideológica possível de abordagem da questão, condicionada à existência de déficit de laicidade dos Estados estudados, o que se observa exemplarmente no Direito inglês."

Palavras-chave: Liberdade de expressão. manifestação de pensamento, crenças religiosas. 


\section{Podemos hacer más: otra forma de pensar el Derecho}

O assunto das caricaturas de Maomé é provavelmente o tema sobre o qual mais se tem escrito nos últimos meses na imprensa. Isso não se deve somente a que no contexto de nosso mundo globalizado tenha sido interpretado por muitos como um dos primeiros episódios do chamado "choque entre civilizações" (entre as duas civilizações que acolhem algo assim como a metade da humanidade), mas também que esse conflito (e suas consequências) reflete um problema interno da nossa civilização ocidental: que peso devemos - estamos dispostos a - dar ao sagrado em nossas sociedades laicas? Até que ponto devemos aceitar que os sentimentos religiosos dos povos, seu sentido de identidade, limitem as liberdades dos indivíduos, o direito de cada qual à liberdade de expressão?

De fato, essa limitação está legalmente prevista. Por exemplo, em nosso código penal (e algo parecido poder-se-ia dizer de quase todas as legislações europeias) se castiga a quem "para ofender os sentimentos de uma confissão religiosa" faça publicamente escárnio de seus dogmas, crenças, ritos ou cerimônias” (art. 525). Ainda que não seja por motivos religiosos (mas talvez diga respeito, de alguma maneira, ao sentido de "sagrado"), a negação do holocausto é, como bem se sabe, um delito em países como a Áustria ou a Alemanha: recentemente se condenou na Áustria, a uma pena de cárcere, o historiador britânico David Irving em essência por haver afirmado que “os nazistas não mataram tantos judeus, nem tinham um plano para o seu extermínio sistemático"; enquanto que na Espanha (de acordo com a doutrina do TC no caso Violeta Friedman), o "negacionismo" não seria um ilícito penal, mas sim um pressuposto de limite justificado ao direito à liberdade de expressão. De forma que, frente à tendência mais ou menos generalizada, na opinião pública de acusar o Islã de estar contra a liberdade de expressão e significar, por isso, uma ameaça para a cultura ocidental, alguns tem esgrimido esta pergunta: não estaremos sendo incoerentes, arbitrários, em tudo isso?

Será que aplicamos um critério em relação com a maneira de entender o sagrado por parte de outras culturas enquanto, simultaneamente, operamos com um critério muito diferente quando o que se trata é proteger nossa própria forma de entender o sagrado?

Pois bem, para determinar se devemos dar ou não razão aos que pensam assim, a primeira coisa a fazer é esclarecer acerca do que se está dizendo e escrevendo sobre o assunto. E dada a profusão de opiniões a respeito, parece imprescindível começar elaborando alguma taxonomia que nos permita introduzir um pouco de ordem. Como, ademais, o assunto das caricaturas de Maomé faz surgir uma pluralidade de perguntas de toda índole (históricas, filosóficas, morais, políticas, jurídicas...), reduzirei todo o problema (consciente de que é uma "redução") a uma única questão: é justificável colocar algum limite à liberdade de expressão por razões exclusivamente de proteção das crenças religiosas de um grupo? Ou, dito de outra maneira: a que se deve atribuir mais valor, à liberdade de expressão ou às crenças religiosas? Na minha opinião, assim colocada, a questão admite, basicamente, quatro respostas.

1) Os fundamentalistas religiosos e os comunitaristas extremos colocam inequivocamente o valor do sagrado, da religião, acima do valor da liberdade de expressão. Está claro que isso é o que ocorre em boa parte da cultura islâmica. Mas o mesmo pode ser dito da doutrina tradicional da Igreja católica (que se condensa no dictum "só há liberdade para a verdade e o bem"), que não parece ter sido abandonada de todo pela hierarquia católica atual. E algo não muito diferente é o que parecem sustentar muitos pensadores comunitaristas de nossos dias que consideram que a religião é, simplesmente, um traço da identidade de alguns grupos sociais, com a consequência de que esses valores comunitários (o "bem comum", tal como entende o grupo) deve prevalecer sobre a autonomia dos indivíduos isolados.

2) Os comunitaristas moderados e os crentes não fundamentalistas (de qualquer religião) tendem a colocar o problema em termos da necessidade de conciliar dois valores da mesma classe. É a opinião que se encontra nos escritos de muitos teólogos, arabistas e cientistas sociais, que mostram uma atitude de "simpatia" ou de "compreensão" frente ao Islã. Um exemplo claro dessa postura (desde uma perspectiva não religiosa) está representado pelo politólogo Sami Naïr, para quem o que teríamos aqui é um enfrentamento entre um "direito sagrado" à liberdade de expressão e outro "direito sagrado" à identidade ( o Islã constituiria o ingrediente básico da identidade política de muitos grupos humanos).

3) Esta última tese é negada pelos liberais moderados (igualmente o é pelos mais radicais). Eu diria que um liberalismo moderado é a posição que melhor permi- 
te dar conta da prática (e da doutrina) jurídica nos países europeus. Por exemplo, o Tribunal Europeu de Direitos Humanos tem desenvolvido nos últimos tempos uma jurisprudência que poderia ser esquematizada assim: a liberdade de expressão não é um direito absoluto e, por isso, quando entra em contradição com outros possíveis direitos ou valores, é necessário proceder a uma ponderação para ver qual tem maior peso, dadas as circunstâncias; a liberdade de expressão goza, em princípio, de certa prioridade, mas pode ser derrotada (digamos, excepcionalmente).

4) Finalmente, os liberais mais radicais consideram que as convicções religiosas por si mesmas não podem triunfar nunca sobre a liberdade de expressão. Não se trata, portanto, de "ponderar" ou, se preferirmos, na ponderação a balança se inclina sempre para o mesmo lado, porque a liberdade de expressão é um valor e as crenças religiosas não; ou melhor dito, estas últimas pertencem exclusivamente à vida privada e constituem, portanto, um valor puramente privado: se o que é ofendido no exercício da liberdade de expressão é uma "crença", não uma pessoa, não há nenhuma razão para que o Direito (o poder público) tenha que intervir. Isso, por certo, é compatível com pensar que, por exemplo, os jornais europeus que não publicaram as caricaturas de Maomé fizeram bem e, inclusive, que agiu mal o jornal holandês no qual originalmente apareceram; mas simplesmente por razões prudenciais, pelo mesmo tipo de razão pela qual não se deve dizer algo que possa incomodar a quem nos está apontando uma pistola, ou jogar um palito de fósforo ao chão se essa ação pode provocar um incêndio.

Voltemos agora à questão da coerência. Qual é, na realidade, o sentido da crítica? Se a classificação anterior for aceitável, então parece óbvio que há um sentido no qual a reação do mundo europeu - ocidental - ao problema das caricaturas de Maomé é incoerente, isto é, não há uma única resposta, mas várias e incompatíveis entre si (ao menos em parte). Mas, por um lado, parece óbvio que essa não pode ser a noção de coerência que aqui se está esgrimindo: quem adota qualquer dessas quatro posturas não pode ser tachado de arbitrário simplesmente pelo fato da sua não ser compartilhada por todos os membros de sua sociedade. E, por outro lado, se a coerência for vista em termos puramente formais, parece também claro que esse não poderia ser o único critério a ser tomado em consideração para dirimir uma questão prática; por exemplo, as posturas extremas da classificação anterior (cada uma em separado) têm talvez mais probabilidade de produzir respostas coerentes, unívocas, aos casos a decidir, simplesmente porque são de mais fácil aplicação, mas isso não constitui uma razão definitiva para optar por alguma das duas e descartar as outras; se poderia pensar também que, dada a complexidade dos casos a resolver, é preferível adotar uma posição mais aberta, mais "flexível", ainda que isso suponha também menor segurança, maior incerteza (mais probabilidade de que se produzam respostas incoerentes).

Considerarei então que a crítica seja dirigida, na verdade, à postura do liberalismo moderado que, como antes dizia, caracteriza, em traços gerais, nossas práticas jurídicas; e que quando se fala de "incoerência" ou de "arbitrariedade" não se faz com um alcance puramente formal: o que se quer dizer é que essa posição é equivocada, produz resultados injustos. Vejamos.

Uma boa maneira de por à prova a coerência interna e a correção de fundo dessa teoria pode consistir em tratar de precisar a doutrina construída nos últimos anos pelo Tribunal Europeu de Direitos Humanos, a qual antes me referia, tomando como base os três casos seguintes, que bem podem ser considerados paradigmáticos.

O primeiro, resolvido pelo Tribunal em agosto de 1994, foi proposto pelo "Instituto Otto-Preminger" contra o Estado austríaco. Essa instituição vienense havia produzido um filme no qual, entre outras coisas, se representava Deus pai como um velho senil, Jesus Cristo como um imbecil e a Virgem Maria como uma leviana. De acordo com um artigo do Direito austríaco que sanciona $\mathrm{o}$ ato de denegrir ou insultar uma pessoa ou ao que é "objeto de veneração por uma igreja ou por uma comunidade religiosa estabelecida em um país", se havia decretado o confisco e a perda das diversas cópias do filme. O problema consistia em decidir se essa medida era compatível com o art. 10 da Convenção Europeia de Direitos Humanos que indica que uma interferência ao exercício da liberdade de expressão somente é admissível se "está prescrita pelo Direito", "persegue um fim lícito" e "é necessária em uma sociedade democrática". O Tribunal, por 6 votos a 3, entendeu que não se havia infringido o artigo, basicamente por essas duas razões: 1) quando a liberdade de expressão afeta opiniões e crenças religiosas, o exercício desse direito inclui "uma obrigação de evitar na maior medida possível expressões que sejam gratuitamente ofensivas para outros [...] e que, portanto, não contribuem a nenhuma forma de debate público capaz 
de promover o progresso dos assuntos humanos"; 2) no momento de determinar a existência e a extensão dessa interferência deve-se deixar "uma certa margem de apreciação" às autoridades nacionais.

É interessante notar que os juízes que sustentaram a opinião contrária esgrimiram, entre outras, estas três razões: 1) a interferência no direito à liberdade de expressão tem caráter excepcional e, por isso, os requisitos que a torna permissível devem ser interpretados restritivamente; 2) a decisão sobre se uma forma de expressão contribui ou não a um debate público que promova o progresso dos assuntos humanos não pode depender da ideia de "progresso" que tenham as autoridades de um país; 3 ) a Convenção não garante um direito à proteção dos sentimentos religiosos: em particular, esse pretendido direito não pode derivar do direito à liberdade religiosa, que inclui o direito a expressar pontos de vista críticos sobre as opiniões religiosas dos demais.

No caso Wingrove contra o Reino Unido (resolvido em novembro de 1996), o senhor Wingrove havia recorrido ao TEDH alegando que a negativa das autoridades britânicas a expedir um certificado de distribuição para um vídeo intitulado "Vissions of Ectassy" vulnerava seu direito à liberdade de expressão reconhecido no art. 10 da Convenção. Uma das cenas do vídeo representava Santa Teresa tendo uma fantasia erótica com a figura de Cristo crucificado e também uma fantasia lésbica, com uma imagem que representava "a psique de Santa Teresa". As autoridades (não judiciais) haviam considerado que o vídeo era pornográfico e que carecia de qualquer valor histórico, religioso ou artístico, pelo que entendiam que qualquer jurado razoável a que fosse apresentado o qualificaria de blasfemo (tal como o delito de blasfêmia está tipificado no Direito britânico) o que levava, definitivamente, a não autorizar sua distribuição; na motivação se recordava que o certificado de distribuição tinha sido expedido anteriormente para filmes como "A vida de Bryan", de Monty Python, ou "A última tentação de Cristo", de Scorsese. O TEDH, seguindo os critérios antes indicados, entendeu que a interferência na liberdade religiosa, nesse caso, perseguia um fim lícito, o de proteger o direito dos cidadãos a não serem ofendidos em seus sentimentos religiosos. Reconhecia que a regulação britânica sobre a blasfêmia, na medida em que só protegia as crenças cristãs, podia não ser compatível com a Convenção, mas entendia que essa não era uma questão sobre a qual teria que se pronunciar. Também considerou que a inter- ferência era "necessária em uma sociedade democrática", porquanto: 1) as razões esgrimidas pelas autoridades nacionais eram relevantes e suficientes (basicamente pelo caráter pornográfico do vídeo e a falta de mérito artístico);2) dadas as circunstâncias, no caso de ser distribuído, o vídeo poderia ser visto por um público que poderia se sentir ofendido.

De toda forma, a decisão não foi unânime. Dos 9 juízes do tribunal, 2 votaram com a maioria, mas formularam votos concorrentes; e houve também 2 outros votos dissidentes. $\mathrm{O}$ aspecto mais controvertido se referia à configuração do delito de blasfêmia no Direito britânico. Um dos magistrados que se apartaram da fundamentação da sentença, ainda que não da decisão, sublinhou que o tribunal deveria ter tornado claro que a base para não outorgar o certificado se encontrava na necessidade de proteger as crenças religiosas (não somente as cristãs), filosóficas ou de qualquer outro tipo: a proibição da distribuição do vídeo teria sido justificada - assinalava - se em lugar do êxtase de Santa Teresa houvesse mostrado, por exemplo, "o anticlerical Voltaire tendo relações sexuais com algum príncipe ou rei". Os dissidentes, por sua vez, colocaram em questão o terceiro dos requisitos (que a medida seja necessária em uma sociedade democrática), um deles porque não via justificada a existência do delito de blasfêmia; e o outro porque, de toda forma, não entendia aceitável que a figura delitiva protegesse unicamente à religião cristã. É interessante notar que na sentença se recorda que os tribunais britânicos se negaram, na oportunidade, a proceder contra "Os versos satânicos" de Salman Rushdie”, precisamente porque entenderam que o delito de blasfêmia não protegia as crenças não cristãs.

Recentemente, em janeiro de 2006, o TEDH resolveu um caso (Giniewski contra França) no qual, novamente, se havia invocado a proteção do art. 10 da Convenção, após a condenação pelos tribunais franceses de um jornalista pelo delito de difamação pública. Paul Giniewski havia publicado um artigo, a propósito de uma das encíclicas do papa João Paulo II (Veritatis Splendor), no qual, em essência, sustentava a tese de que certos princípios da religião católica que a encíclica em questão voltava a afirmar (a Igreja católica como única detentora da verdade divina, a superioridade da "nova aliança" frente à "antiga aliança"), unidos ao antijudaismo de algumas passagens das Escrituras, haviam favorecido o Holocausto ("conduzem ao anti-semitismo e formaram o terreno em que germinou a ideia e a realização de Auschwitz"). Como 
nos outros dois casos, a motivação do TEDH se centrou no requisito de saber se é necessária a interferência na liberdade de expressão em uma sociedade democrática. O Tribunal (nesse caso, por unanimidade) entendeu que não e, em consequência, decidiu em favor do jornalista, fundamentalmente por essas duas razões: 1) a ingerência na liberdade de expressão não se correspondia com uma "necessidade social imperiosa", posto que o artigo havia querido elaborar uma tese, obviamente discutível, sobre a origem do Holocausto e supunha, por isso, uma contribuição a um debate de ideias, sem abrir uma polêmica gratuita; 2) a sanção imposta pelas autoridades nacionais era desproporcional e poderia levar a dissuadir a imprensa e os autores de participar na discussão de questões de interesse geral.

Pois bem, a partir daqui poderíamos apresentar uma espécie de experimento mental que consistiria em adivinhar o que decidiria o TEDH no caso de que se lhe chegasse o conflito desatado pela publicação das caricaturas de Maomé (ou de "Os versos satânicos" de Salman Rushdie). Ou seja, imaginemos que um Estado europeu, aplicando sua própria legislação, tivesse condenado os autores de (algumas das) caricaturas de Maomé a uma pena de multa ou houvesse tomado alguma medida contrária a sua publicação; algo, por certo, inteiramente possível onde esteja vigente um artigo como o 525 do código penal espanhol. Se os autores das vinhetas e o jornal tivessem recorrido ao TEDH alegando que se houvesse infringido seu direito à liberdade de expressão encontrado no art. 10 da Convenção, a resposta mais provável, na minha opinião, seria a seguinte: o tribunal, aplicando sua própria jurisprudência (pressuponho que atuaria em coerência com a doutrina estabelecida até agora), consideraria (seguramente por maioria) que a medida em questão não vulnera o art. 10. Sua decisão se fundamentaria provavelmente nessas duas razões: 1) as caricaturas (por exemplo, a do profeta com um turbante que esconde uma bomba, ou dizendo - na entrada do éden muçulmano - a alguns mujahidines que acabam de imolar-se que já entraram tantos que não há virgens huries disponíveis) são gratuitamente ofensivas, não contribuem a um debate de ideias nem têm especial mérito artístico; 2) a limitação da liberdade de expressão corresponde a uma necessidade social imperiosa.

O resultado desse experimento mental leva então a que - até certo ponto - se possa tachar de incoerentes aqueles que defendem a liberdade de expressão dos autores das caricaturas baseando-se em uma espécie de "direito à irreverência" incorporado na cultura ocidental e europeia, dado que nossas práticas jurídicas desmentem que exista tal direito; mas não há por que pensar que o juízo de incoerência valha também para a própria prática do TEDH. Melhor dito, se a jurisprudência do Tribunal pode produzir resultados incoerentes, arbitrários, isso se deve à existência de Direitos como o britânico que, segundo vimos, contem um delito de blasfêmia que somente protege os sentimentos religiosos dos cristãos (mais especificamente: dos anglicanos). Mas, em verdade, todo o mundo parece estar de acordo que essa norma seja injusta, e que sua razão de ser não é outra senão a existência de certas peculiaridades (anomalias) do common law inglês que permitem a existência de figuras delitivas não estabelecidas pelo legislador (e que contradiriam o princípio da legalidade penal, tal como entendido no continente). Entretanto, não pareceria haver nenhuma incoerência se a legislação de base fosse, por exemplo, a espanhola, na qual o que se protege não são somente as crenças religiosas (de qualquer religião), mas também as não religiosas, pois o legislador do código penal, no parágrafo antes descrito do art. 525 acrescenta isto: "nas mesmas penas incorrerão os que façam publicamente escárnio, verbalmente ou por escrito, de quem não professa religião ou crença alguma”.

Então vejamos. Teríamos de considerar por isso - porque não produz resultados incoerentes, arbitrários - que uma norma como a do art. 525 do código penal espanhol é justa e que, em consequência, não haveria nada a ser alterado na jurisprudência do TEDH baseada em ponderar a liberdade de expressão e as crenças religiosas com os critérios que acabamos de ver? Creio que não. Parece-me melhor que os que têm razão nesse ponto são os liberais mais radicais que negam a legitimidade de proteger penalmente (e, em geral, com medidas jurídicas ou políticas) os sentimentos religiosos, não religiosos ou irreligiosos das pessoas. $\mathrm{O}$ delito estabelecido no código penal espanhol carece, na minha opinião, de justificação e não me parece nada claro que também não seja incoerente. Como acabamos de ver, o legislador se esforça para construir a figura de maneira que não suponha uma desigualdade de tratamento entre crentes e não crentes mas, simplesmente, não consegue. Por um lado essa configuração do tipo penal leva a postular categorias de difícil compreensão (não é um oximoro falar de "crenças dos que não professam crença alguma”?), espe- 
cialmente quando se percebe que (de acordo com o título da seção em que se localiza o artigo) se trataria de um delito "contra os sentimentos religiosos". Por outro lado, no artigo há uma clara assimetria de tratamento dispensado aos crentes e não crentes: em relação aos primeiros, o que é proibido é fazer escárnio "de seus dogmas, ritos ou cerimônias", assim como vexar "quem os professe ou pratique”, enquanto que em relação aos segundos, a única conduta proibida é a de fazer escárnio de "quem não professe religião ou crença alguma”. ${ }^{3}$ No que se refere à jurisprudência do TEDH, minha opinião é que deveria se modificar no sentido apontado em algum dos votos particulares que, na realidade, viria a ser o do liberalismo que classifiquei de "radical".

A razão seguramente de maior peso para sustentar essa última posição ("radical” possui, algumas vezes, um sentido elogioso que não há porque retirar da língua) é que ela se liga à defesa de valores universais como (além da liberdade) a igualdade e a verdade. A única maneira de não produzir discriminações por razão de religião é considerar a liberdade religiosa como uma liberdade negativa que se satisfaz se, e somente se, o Estado é estritamente laico (o que, por certo, não ocorre hoje na Espanha). E talvez o aspecto mais ameaçador da polêmica em torno das caricaturas de Maomé radica em que a aceitação de estabelecer limites à liberdade de expressão para proteger não as pessoas, mas as suas crenças (ou seja, a postura mais "tolerante") parece ir acompanhada de um relativismo moral e cultural que tende a situar as crenças religiosas no mesmo plano das teorias científicas e dos fatos históricos. Podemos deixar para outra ocasião a tarefa de mostrar por que, a propósito da liberdade de expressão, devem estar unidos o caráter laico do Estado, a universalidade da moral e a objetividade das verdades científicas.

3 O texto completo do art. 525 é o seguinte: "1. Incorrerão em pena de multa de oito a doze meses os que, para ofender os sentimentos dos membros de uma confissão religiosa, façam publicamente, verbalmente, por escrito ou mediante qualquer tipo de documento, escárnio de seus dogmas, crenças, tios ou cerimônias, ou vexem, também publicamente, a quem os professem ou pratiquem. 2. Nas mesmas penas incorrerão os que façam publicamente escárnio, verbalmente ou por escrito, de que não professem religião ou crença alguma." 